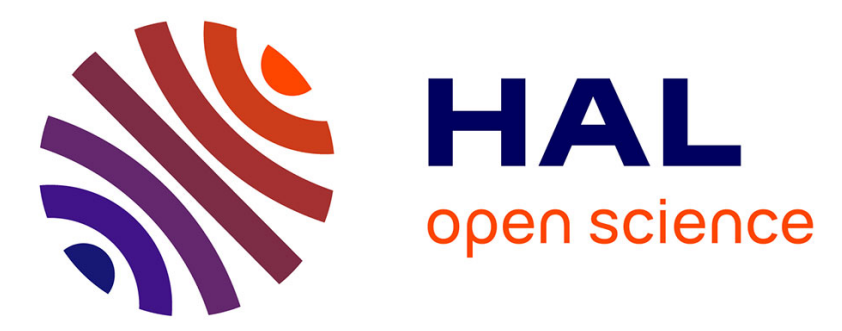

\title{
Modeling Energy Migration for Upconversion Materials
}

G. Ledoux, David Amans, Marie-France Joubert, Benoit Mahler, S. Mishra, S. Daniele, Christophe Dujardin

\section{To cite this version:}

G. Ledoux, David Amans, Marie-France Joubert, Benoit Mahler, S. Mishra, et al.. Modeling Energy Migration for Upconversion Materials. Journal of Physical Chemistry C, 2018, 122 (1), pp.888-893. 10.1021/acs.jpcc.7b10113 . hal-01677488

\section{HAL Id: hal-01677488 https://hal.science/hal-01677488}

Submitted on 8 Jan 2018

HAL is a multi-disciplinary open access archive for the deposit and dissemination of scientific research documents, whether they are published or not. The documents may come from teaching and research institutions in France or abroad, or from public or private research centers.
L'archive ouverte pluridisciplinaire HAL, est destinée au dépôt et à la diffusion de documents scientifiques de niveau recherche, publiés ou non, émanant des établissements d'enseignement et de recherche français ou étrangers, des laboratoires publics ou privés. 


\title{
Modeling Energy Migration for Upconversion Materials
}

\author{
G. Ledoux, ${ }^{* \dagger \oplus}$ D. Amans, ${ }^{\dagger}$ M.-F. Joubert, ${ }^{\dagger}$ B. Mahler, ${ }^{\dagger}$ S. Mishra, ${ }^{\ddagger}$ S. Daniele, ${ }^{\ddagger}$ and C. Dujardin ${ }^{\dagger}$ \\ †Univ Lyon, Université Claude Bernard Lyon 1, CNRS, Institut Lumière Matière, F-69622 Lyon, France \\ "Univ Lyon, Université Claude Bernard Lyon 1, CNRS, Institut de Recherches sur l'Environnement et la Catalyse de Lyon, F-69622 \\ Lyon, France
}

\section{Supporting Information}

ABSTRACT: One of the key issues in upconversion materials is the design of an appropriate complex nanoarchitecture to control energy migration. We propose here a numerical tool based on a Monte Carlo approach capable of modeling the energy migration in particles with diameters of up to a few tens of nanometers. To validate the approach, the obtained results are compared with a wide range of published experimental data. The proposed simulation allows us to guide the optimal design strategies to develop upconverting nanoparticles for light-harvesting applications.

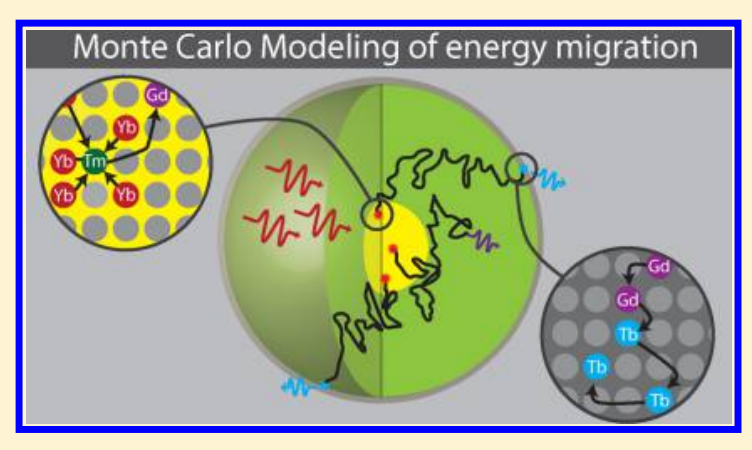

\section{INTRODUCTION}

Up-conversion is a well -known optical process that allows us to convert the absorption of low-energy photons into higher energy photon emission. It was demonstrated in the late 1950s by Bloembergen. ${ }^{1}$ A few years later, Auzel $^{2,3}$ showed that it could be combined with energy transfer. Such a process is known as APTE (addition de photons par transfert d'énergie) or ETU (energy transfer upconversion). It has been widely studied as a fundamental process and is currently commonly used in bioimaging ${ }^{4}$ and for photovoltaic applications. ${ }^{5}$ This process may involve various sequences of cooperative effects and energy transfers. Wang et al. demonstrated in 2011 that suitable core-shell structures enable us to force irreversible energy migration of the excited states. ${ }^{6}$ A great number of applications have been developed in this spirit, and numerous new geometrical designs have been proposed. ${ }^{7-18}$

These experimental demonstrations are based on the analysis of the emission efficiency measurements for various core-shell structures, where active elements are supposed to be homogeneously distributed. Because energy transfers are strongly dependent on the acceptor-donor distances, natural fluctuations and even gradients of concentrations might have a significant impact. It is crucial to evaluate their effects to properly describe the observed data and to optimize systems. The goal is to design a model accounting for the complex core-shell structure on the atomic scale and containing various interfaces, which cannot be achieved by a simple analytical model of diffusion. Villanueva-Delgado et al. have recently proposed an approach based on the population equation of individual elements, which has been solved, ${ }^{19}$ but the system is then limited to thousands of atoms, which is two orders of magnitude smaller than the particles considered in our work and developed experimentally. We propose here a Monte Carlo (MC)-based simulation to estimate these energy- transfer efficiencies and trajectories that help in the design of optimized systems on the atomic scale. Such designs of complex structures allow us to fully control the migration of excitation from a sensitizer to an active center, including special functions, such as diode-like layer regarding these migrations, which are crucial in the field of light harvesting for photocatalysis. Monte-Carlo-based approaches to model upconversion processes have already been proposed, but they have been based on a kinetic approach to model the dynamics of the upconversion. ${ }^{20,21}$ They therefore evaluated simple geometries considering only one composition. Another work by Wang et al. ${ }^{22}$ is closer to our approach. They modeled the energy migration among the $\mathrm{Yb}$ ions sublattice for two different crystalline structure. Compared with our work they only considered first neighbors for the transfer and only homoatomic transfers. Here, instead, we consider all reasonably possible transfers, including those between ions of different nature.

\section{RESULTS AND DISCUSSION}

The proposed model aims in estimating the efficiency of energy migration of a high-energy excited state toward the outer surface of a core-shell nanoparticle (NP) where photocatalysis occurs. In our model, we consider a core made of an up-converting material in which the high-energy excitation state is reached through a primary optical excitation, as schemed in Figure 1. The excitation can then be transported to the outer layer by nonradiative energy transfer. The whole process is called energy migration upconversion (EMU), as introduced by Wang et al. ${ }^{6}$ When the high-energy excitation

Received: October 12, 2017

Revised: November 29, 2017

Published: December 14, 2017 


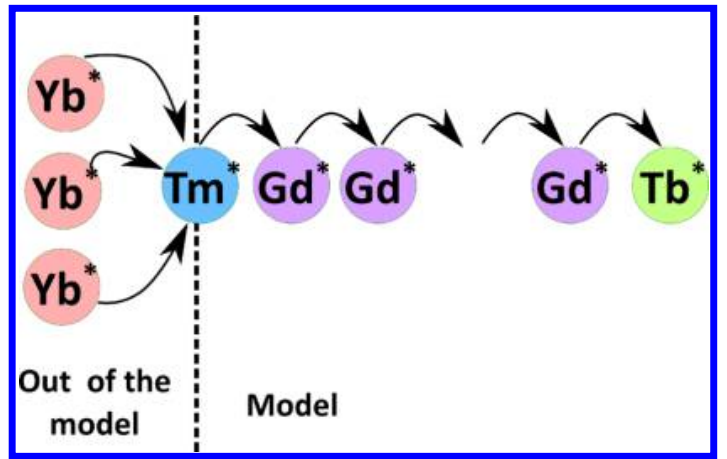

Figure 1. Scheme of the process modeled. The upconversion process is not modeled; only the transfer between $\mathrm{Tm}, \mathrm{Gd}$, and $\mathrm{Tb}$ is modeled.

reaches the surface, the system is considered as ready for photocatalysis. Despite the fact that we are focusing our attention on converters for the photocatalysis effect, the model can be generalized to other configurations. We are thus considering a core-shell NP containing potentially multiple shells. For validation, we have selected $\beta-\mathrm{NaGdF}_{4}$, a material benefiting from abundant literature in terms of energy-transfer and back-transfer efficiency data. It can be doped with various activators, and a core-shell structure having different optical functions can be prepared with the same host, with an epitaxylike interface, considered as perfect.

We are considering $\beta-\mathrm{NaGdF}_{4}$ doped with ytterbium and thulium ions as the core. Ytterbium is present at high concentration to ensure a strong infrared light absorption and to efficiently promote thulium ions into a high excited states (with energy above the ${ }^{1} \mathrm{I}_{6}$ level; see Figure S1). From that level, $\mathrm{Tm}^{3+} \rightarrow \mathrm{Tm}^{3+}$ energy transfer may occur, but crossrelaxation leads to step-by-step energy losses, as explained by Liu et al. ${ }^{23} \mathrm{Tm}^{3+} \rightarrow \mathrm{Gd}^{3+}$ energy transfer can occur between ions being separated by short distances, while $\mathrm{Gd}^{3+} \rightarrow \mathrm{Gd}^{3+}$ energy transfer is very efficient. Contrary to $\mathrm{Tm}^{3+}$, crossrelaxation cannot occur between $\mathrm{Gd}^{3+}$ ions. It is why $\beta$ $\mathrm{NaGdF}_{4}$ is preferred to $\beta-\mathrm{NaYF}_{4} \cdot \mathrm{Gd}^{3+}$ from the host acts as an energy mediator through its ${ }^{6} \mathrm{P}_{i},{ }^{6} \mathrm{I}_{i}$, or ${ }^{6} \mathrm{D}_{i}$ multiplets. On the basis of these processes, the excitation is redistributed among the different ions constituting the structure and the model aims to evaluate the contributions of the different ions to the emission and the fraction of excitation reaching the surface of the nanocrystal. As an indicator of the reached surface, we consider an outer layer of $\beta$ - $\mathrm{NaGdF}_{4}: \mathrm{Tb}^{3+}$. $\mathrm{Tb}^{3+}$ excited states show a good resonance with $\mathrm{Gd}^{3+}$ excited states, allowing an efficient transfer from $\mathrm{Gd}^{3+}$. In addition, our results can be compared with the obtained results from literature through the observed typical green emission intensity from the $\mathrm{Tb}^{3+}$ ions. We particularly focus our attention on the energy migration depending on the compositions of the nanocrystal.

Details of the numerical calculations are given in the Supporting Information. The various transfer probabilities, namely, $\mathrm{Tm}^{3+} \rightleftharpoons \mathrm{Tm}^{3+}, \mathrm{Tm}^{3+} \rightleftharpoons \mathrm{Gd}^{3+}, \mathrm{Gd}^{3+} \rightleftharpoons \mathrm{Gd}^{3+}, \mathrm{Gd}^{3+} \longrightarrow$ $\mathrm{Tb}^{3+}$, and $\mathrm{Tb}^{3+} \rightleftharpoons \mathrm{Tb}^{3+}$ used in our Monte Carlo code, are based on the critical radius model considering dipole-dipole interaction. The critical radius $R_{\mathrm{c}}$ is the distance between a donor and an acceptor for which the energy-transfer probability from donor to acceptor is equal to the radiative probability of the donor. Considering dipole-dipole interactions the relative probability of transfer is proportional to $\left(R_{c} / R\right)^{6},{ }^{24}$ where $R$ is the real distance from donor to acceptor.
While the physical reason comes from a change of transition rate, using a critical radius approach allows us to avoid the time parameter in the model. The transfer between two species can then be described by only one parameter $R_{\mathrm{c}}$ in addition to the geometrical layout of the atoms. The parameters $R_{c}^{\text {start }}$, considered as initial values, are obtained from literature and summarized in Table 1. As described later, these initial values are not the best values allowing us to fit the experimental data, and the optimized ones are then deduced $\left(R_{\mathrm{c}}^{\mathrm{opt}}\right)$.

Table 1. List of Critical Radii Used for the Estimation of the Dipole-Diplole Energy Transfer ${ }^{a}$

$\begin{array}{ccc}\mathrm{D} \rightleftharpoons \mathrm{A} & R_{\mathrm{c}}^{\text {start }}(\mathrm{nm}) & R_{\mathrm{c}}^{\text {opt }}(\mathrm{nm}) \\ \mathrm{Gd} \rightleftharpoons \mathrm{Gd} & 0.39-0.6 & 0.75 \\ \mathrm{Gd} \rightarrow \mathrm{Tb} & 1.38 & 0.9 \\ \mathrm{Gd} \rightarrow \mathrm{Tm} & & 0.5 \\ \mathrm{Tm} \rightarrow \mathrm{Gd} & & 0.5 \\ \mathrm{~Tb} \rightleftharpoons \mathrm{Tb} & 1.2-1.42 & 1.4 \\ \mathrm{~Tb} \rightarrow \mathrm{Tm} & & 0.75 \\ \mathrm{Tm} \rightarrow \mathrm{Tb} & & 0.5 \\ \text { are derived from Kiliaan et } \mathrm{al}^{25} & \end{array}$

We selected the Wichmann-Hill random number generator, which offers the best compromise between the calculation speed and randomness. To generate the atomic positions, we use a representative supercell of the considered material described as a list of atomic positions $(x, y, z)$. The supercell is then reproduced in the three directions, generating a cube whose sides are larger than the particle diameter. As previously explained, we applied our model on $\beta-\mathrm{NaYF}_{4}$ and $\beta-\mathrm{NaGdF}_{4}$ hosts. According to the CCDC file 872707, the space group for $\beta$ - $\mathrm{NaGdF}_{4}$ is $P 6$ with unit-cell parameters $a=6.0400(10) \AA$ and $c=3.6100(6) \AA$ and a cell volume of $114.05(3) \AA^{32.6}$

$\mathrm{Y}, \mathrm{Gd}, \mathrm{Yb}, \mathrm{Tm}$, and $\mathrm{Tb}$ ions are randomly distributed according to the desired composition. The nanocrystal design may include multilayers assuming perfect interfaces. We have considered the cell parameter of $\mathrm{NaGdF}_{4}$, whatever the content of the metallic ions. Note that the cell parameter of $\mathrm{NaYbF}_{4}$ is similar to $<2 \%$ difference $\left(a=5.927 \AA^{27}\right)$ and that the cores we are considering contain at least $50 \%$ of $\mathrm{Yb}^{3+}$.

Because the dipole-dipole transfer is strongly sensitive to the interatomic distance, fluctuations may be observed from one distribution to another. For each composition, we have performed the calculations over 250 randomly prepared geometries. For each generated geometry we evaluated over 5000 tracks the probability for an excitation to reach the surface when the core has been excited. From one step to the next, the transfer probability for a given pair of ion is deduced from Table 1. We neglected all of the transfer with a characteristic time one hundred times higher than the radiative lifetime of the donor. In other words we consider only acceptor ions that are at smaller distances than $R_{c} \cdot 99^{1 / 6}$ from the donor ion. The distribution of probability density of the remaining process is then normalized to 1 for each donor, thus becoming a distribution of probabilities. The sequence of energy transfers ends when a radiative recombination occurs. Typical tracks are presented in the Supporting Information (Figure S2).

Our model relies on the measure of the critical radius of transfer for the different possible pairs of ions obtained from the literature. These values are nevertheless scarce and even sometimes contradictory for the compositions we are interested in. Kiliaan et al. have studied the energy transfers 


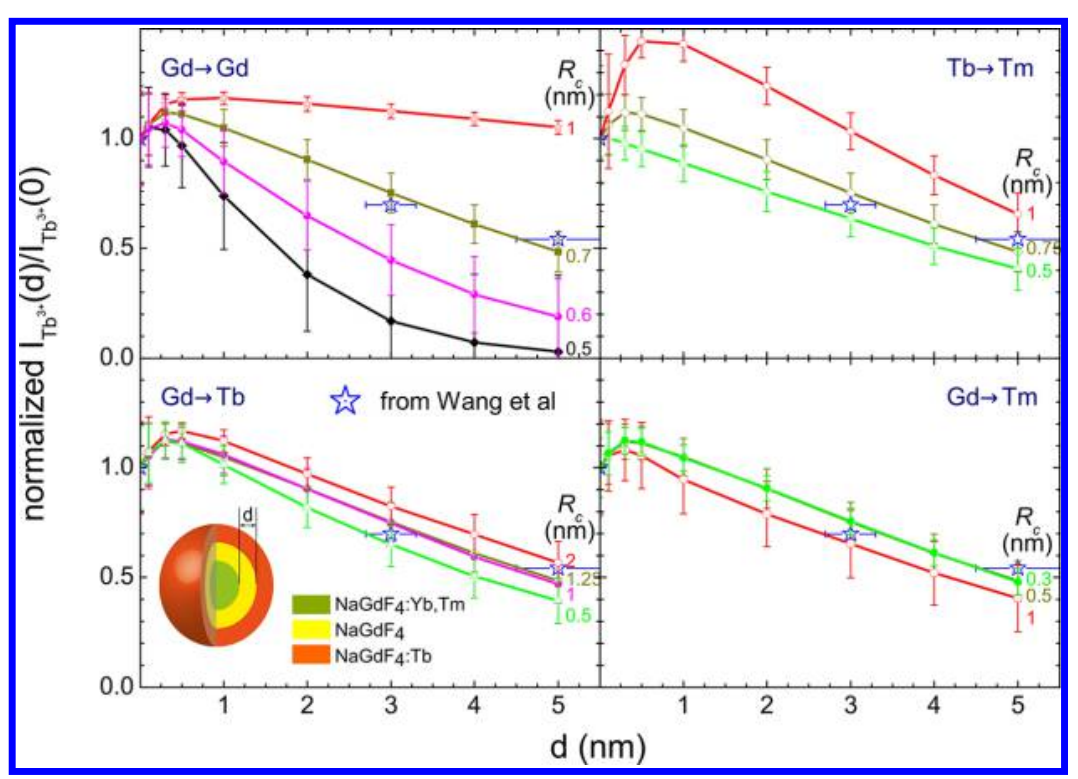

Figure 2. Effect of the change of $R_{\mathrm{c}}$ value for different couples of donor-acceptor ions on the evolution of the normalized $\mathrm{Tb}$ emission $I_{\mathrm{Tb}}{ }^{3+}(d) /$ $I_{\mathrm{Tb}^{3+}}(0)$ for core-shell-shell nanoparticles. $\mathrm{Tm}^{3+}$ and $\mathrm{Tb}^{3+}$ are separated by a NaGdF 4 shell layer of varying thickness $d$. The blue star points are derived from figure $3 \mathrm{~d}$ in ref 6 . The lines are the results obtained from the modeling with varying values of critical radii corresponding to different transfer noted on the upper left or right corner of each layer, while the other $R_{\mathrm{c}}$ values are kept at their optimal values (Table 1 ). The dark yellow curve corresponds to the best-fit values. Error bars are for $95 \%$ confidence intervals $(2 \sigma)$.

in $\mathrm{Na}(\mathrm{Y}, \mathrm{Gd}) \mathrm{F}_{4}$ doped with $\mathrm{Ce}^{3+}$ and $\mathrm{Tb}^{3+}$. 25 They derived a critical radius for $\mathrm{Gd}^{3+}$ to $\mathrm{Gd}^{3+}$ between 0.39 and $0.6 \mathrm{~nm}$. At the same time, they deduced a critical radius for the transfer ${ }^{5} \mathrm{D}_{3} \rightarrow{ }^{7} \mathrm{~F}_{0}$ to ${ }^{7} \mathrm{~F}_{6} \rightarrow{ }^{5} \mathrm{D}_{4}$ in $\mathrm{Tb}^{3+}$ of $\sim 1.42 \mathrm{~nm}$. Later Fournier et al. found a value of $1.2 \mathrm{~nm}$ for the same transfer between $\mathrm{Tb}^{3+}$ ions. ${ }^{28}$ From the value of transfer rates calculated by Kiliaan et al., one can also deduce a value for the $\mathrm{Gd}^{3+}$ to $\mathrm{Tb}^{3+}$ transfer of $1.38 \mathrm{~nm}$. It should be noted, however, that there are huge discrepancies in the literature on the critical radii from one composition to another and even for the same compositions. For instance, the $\mathrm{Gd}^{3+}$ to $\mathrm{Gd}^{3+}$ critical radius varies from $0.39^{25}$ to $1.86 \mathrm{~nm} .^{29}$ Additionally no critical radius value was found for $\mathrm{Tm}^{3+}$ to $\mathrm{Gd}^{3+}$ energy transfer, but this particular one has a marginal effect, as explained later. Other energy transfer can be discarded. Indeed, $\mathrm{Tb}^{3+} \rightarrow \mathrm{Gd}^{3+}$ cannot occur because the excited state ${ }^{5} \mathrm{D}_{2}$ of $\mathrm{Tb}^{3+}$ lies below the $\mathrm{Gd}^{3+}$ excited states. Therefore, once the energy has been transferred to continuum of excited states above the level of terbium ions, the energy will rapidly decrease by phonon emission down to the ${ }^{5} \mathrm{D}_{3}$ level without any back-transfer capabilities. Similarly $\mathrm{Tm}^{3+}$ to $\mathrm{Tm}^{3+}$ cross-relaxation can happen but generally only for excited levels that are below those of gadolinium. $\mathrm{Tm}^{3+}$ can, in principle, transfer to $\mathrm{Tb}^{3+}$ ions directly, but no values are available in the literature for transfer from the high states of $\mathrm{Tm}^{3+}\left({ }^{1} \mathrm{D}_{2}\right.$ or above) to $\mathrm{Tb}^{3+}$.

The $R_{c}$ values have then been optimized by making a multiparameter optimization of their values to best fit a number of experimental data detailed below. First, we validated our model considering the structures studied by Wang et al. ${ }^{6}$ Figure 2 presents the evolution of $\mathrm{Tb}^{3+}$ emission for coreshell-shell nanoparticles in which $\mathrm{Tm}^{3+}$ ions are separated from $\mathrm{Tb}^{3+}$ ions by an undoped $\mathrm{NaGdF}_{4}$ layer. This structure is particularly suitable for the analysis of the transfer between $\mathrm{Gd}$ ions. Because the $R_{c}$ parameters obtained from literature contain some uncertainties, optimization is required. We are thus facing a multiparameter problem. It requires us to order the importance of potential $R_{\mathrm{c}}$ fluctuations on the efficiency.
We have tuned each ion pair's $R_{c}$ values around the initial value for several thicknesses of the undoped layer. The evolution shown in Figure 2 allows us to estimate that the maximum sensitivity on the overall efficiency comes from the $\mathrm{Gd}^{3+} \rightarrow$ $\mathrm{Gd}^{3+}$ critical value. $R_{\mathrm{c}}$ for $\mathrm{Tb}^{3+} \rightarrow \mathrm{Tm}^{3+}$ transfer plays a role mainly for weak undoped thicknesses. Then, the $\mathrm{Gd}^{3+} \rightarrow \mathrm{Tb}^{3+}$ and $\mathrm{Gd}^{3+} \rightarrow \mathrm{Tm}^{3+} R_{\mathrm{c}}$ values marginally affect the curves. Finally, we have not detected any significant changes when changing $R_{\mathrm{c}}$ for the $\mathrm{Tm}^{3+} \rightarrow \mathrm{Gd}^{3+}, \mathrm{Tm}^{3+} \rightarrow \mathrm{Tb}^{3+}$, and $\mathrm{Tb}^{3+} \rightarrow$ $\mathrm{Tb}^{3+}$ transfer. The curves are thus not presented here but in the Supporting Information, Figure S4.

When comparing the simulations to the experimental data, it clearly appears that the $R_{\mathrm{c}}$ values proposed by Kiliaan et al. ${ }^{25}$ $(0.4-0.6 \mathrm{~nm})$ for the $\mathrm{Gd}^{3+}$ to $\mathrm{Gd}^{3+}$ transfer $R_{\mathrm{c}}$ are underestimated. $R_{\mathrm{c}}^{\text {opt }}$ of about 0.7 to $0.75 \mathrm{~nm}$ better fit the data. The multiparameter optimized data are listed in Table 1. From the experiments, the evolution of the efficiency as a function of the undoped layer thickness appears monotonic. Nevertheless, the investigated thicknesses were 0,3 , and $5 \mathrm{~nm}$. The simulation highlights that a maximum occurs for thicknesses below $1 \mathrm{~nm}$. On one hand, the process benefits from an increase in the thickness of the undoped layer to limit the back transfer $\mathrm{Gd}^{3+} \rightarrow \mathrm{Tm}^{3+}$. On the contrary, when the $\mathrm{Gd}^{3+} \rightarrow \mathrm{Gd}^{3+}$ transfer probability is high, having a large thickness increases the time spent in the intermediate layer, which is always detrimental to the excitation migration toward the surface, even in perfect crystals. Our model allows us to obtain the optimum thickness of the undoped $\mathrm{NaGdF}_{4}$, which was not observed by the experiments and which is in the range of a few atomic layers.

To demonstrate the crucial role of the intermediate antiback-transfer layer, the results can be compared considering $\mathrm{NaYF}_{4}$ instead of $\mathrm{NaGdF}_{4}$. Contrary to $\mathrm{Gd}^{3+}, \mathrm{Y}^{3+}$ cannot lead to any energy transfer toward other active ions. This intermediate layer thus acts as a passive spacer. Experimental results were published in 2012 by Su et al. ${ }^{16}$ By comparing our results with their experimental data (see Supplementary Figure 
S5), we can better optimize the values of $\mathrm{Gd}^{3+} \rightarrow \mathrm{Tb}^{3+}$ and $\mathrm{Tb}^{3+} \rightarrow \mathrm{Tm}^{3+}$ critical radii. From this comparison with the two experimental multilayered nanoparticles, a reasonable set of critical radius values can be extracted that differ from the initial values summarized in Table 1 . Those values are used in the following text.

We have considered up to now a random distribution of the cations according to a defined composition. This statement can, in fact, be not true, and some deviations might be observed due to the segregation that our model is able to reproduce. Wang et al. ${ }^{6}$ have considered a core made of $\mathrm{NaY}_{x} \mathrm{Gd}_{(1-x)} \mathrm{F}_{4}: \mathrm{Yb}, \mathrm{Tm}$ and a shell of $\mathrm{NaGdF}_{4}: \mathrm{Tb}$. It appears that for any reasonable range of critical radius the simulation (red curve) cannot correctly reproduce their data (blue stars), as shown in Figure 3. At low $\mathrm{Gd}^{3+}$ concentration the

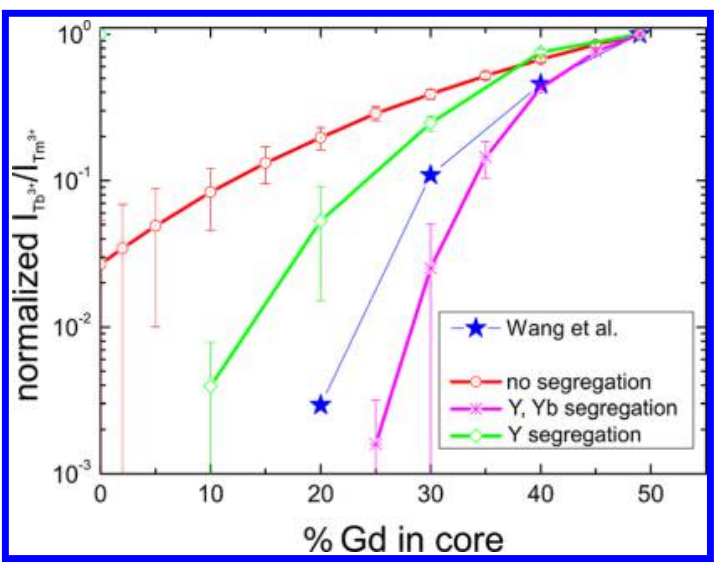

Figure 3. Evolution of the normalized $\mathrm{Tb}$ emission for core-shell nanoparticles with $\mathrm{Tm}^{3+}$-doped $\mathrm{NaY}_{x} \mathrm{Gd}_{(1-x)} \mathrm{F}_{4}$ in the core and $\mathrm{NaGdF}_{4}$ doped with $\mathrm{Tb}^{3+}$ in the shell. The blue stars are derived from Figure $3 \mathrm{c}$ in Wang et al. ${ }^{6}$ The other lines are the results obtained from the modeling under different conditions. Red circles correspond to $\mathrm{NaY}_{x} \mathrm{Gd}_{(1-x)} \mathrm{F}_{4}: \mathrm{Yb}, \mathrm{Tm} @ \mathrm{NaGdF}_{4}: \mathrm{Tb}$. For green rhombus, yttrium ions have been segregated in an intermediate undoped $\mathrm{NaYF}_{4}$ layer. For magenta stars, both yttrium and ytterbium have been segregated. In both segregated structures the overall number of each ions has been kept identical. Error bars are for $95 \%$ confidence intervals $(2 \sigma)$.

simulation predicts a transfer efficiency toward the outer shell one order of magnitude higher than observed. The experimental data would in first approximation suggest that the transfer $\mathrm{Gd}^{3+} \rightarrow \mathrm{Tb}^{3+}$ and $\mathrm{Tm}^{3+} \rightarrow \mathrm{Tb}^{3+}$ is less efficient than expected, but because the critical radii are physical constants, the only acceptable explanation is a modification of the mean $\mathrm{Gd}^{3+}-\mathrm{Tb}^{3+}$ and $\mathrm{Tm}^{3+}-\mathrm{Tb}^{3+}$ average distances. Such a situation may occur if the distribution of the cations is not homogeneous in the case of the solid solution. We have thus considered hypothetical distribution coefficients to design the nanoparticle for the modeling. Two examples of such a segregation are presented in Figure 3. In the first case (green) we suppose that yttrium ions are segregated to the surface and the core thus forms a core-shell system, with the core being made of $\mathrm{NaGdF}_{4}$ and the shell made of $\mathrm{NaYF}_{4}$, according to the composition of the supposed solid solution. As an illustration, for $25 \% \mathrm{Gd}^{3+}$ in the core the intermediate $\mathrm{NaYF}_{4}$ layer has a thickness of $0.75 \mathrm{~nm}$. In the second case (magenta) we consider that $\mathrm{Y}^{3+}$ are segregated together with $\mathrm{Yb}^{3+}$ so that the intermediate layer is a $\mathrm{NaYF}_{4}: \mathrm{Yb}^{3+}(50 \%)$. For the same example as above ( $25 \%$ gadolinium), the thickness of the intermediate layer is then $1.6 \mathrm{~nm}$. The best fit would be obtained for an intermediate case where part of yttrium and ytterbium atoms are segregated. It is noteworthy that the thickness of the intermediate layer is still pretty small and therefore difficult to detect experimentally by electron energy loss (EELS) or energy-dispersive X-ray spectroscopy on a transmission electron microscope. Such segregation might be smoother than a real core-shell structure. It nevertheless reproduces the tendency. Apart from the potential distribution coefficient, we have noticed that the fluctuation of geometries coming from the random generation of structures leads to a spread of efficiencies of $\sim 15 \%$ (see Supplementary Figure S6). It suggests that special configurations of active ion distributions are significantly more efficient.

It is also interesting to compare our model to results obtained for more complex systems such as those developed for photocatalysis. Since 2013 there has been a number of studies on the combination of upconverting nanoparticles with titania particles to create some IR-sensitive photocatalyst. While many teams ${ }^{30-34}$ have synthesized $\mathrm{NaYF}_{4}: \mathrm{Yb}, \mathrm{Tm}$ particles decorated with titania nanoparticles, Chen et al. ${ }^{35}$ have synthesized $\mathrm{NaGdF}_{4}: \mathrm{Yb}, \mathrm{Tm}$ decorated with titania. For yttrium-based systems, no increased solar-driven photocatalysis was observed. For gadolinium-based systems a strong increase was observed. If we consider two model systems of yttriumand gadolinium-based core surrounded by a shell of terbiumdoped $\mathrm{NaYF}_{4}$ used to mimic the titania, then we observe a huge difference in terbium emission, as can be evidenced on Figure 4. This stresses the importance of gadolinium energy

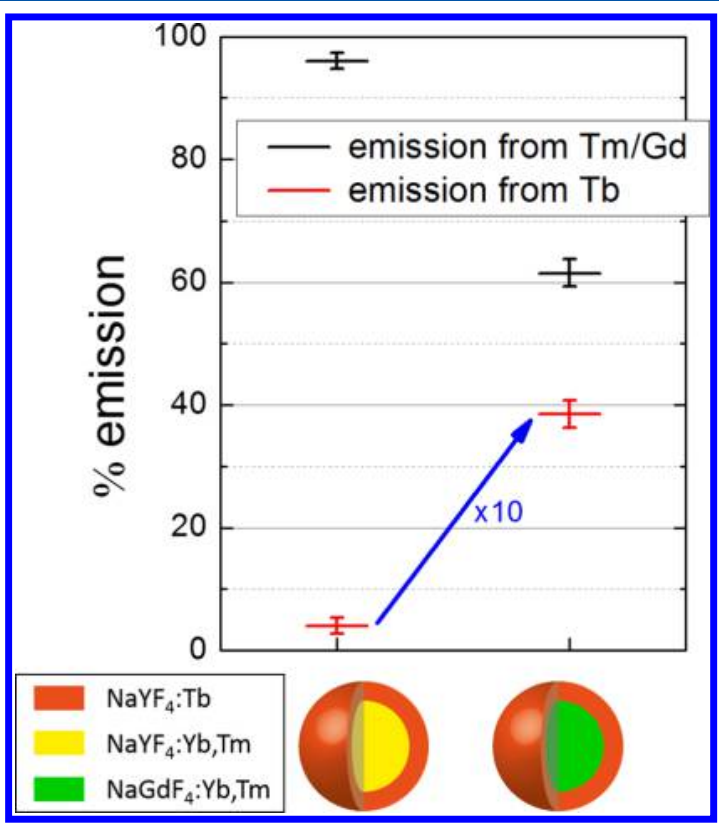

Figure 4. Amount of $\mathrm{Tm}^{3+}$ emission compared with $\mathrm{Tb}^{3+}$ plus $\mathrm{Gd}^{3+}$ emission for two different core-shell structures. On the left, $\mathrm{NaYF}_{4}: \mathrm{Yb}, \mathrm{Tm} @ \mathrm{NaYF}_{4}: \mathrm{Tb}$, and on the right, $\mathrm{NaGdF}_{4}: \mathrm{Yb}, \mathrm{Tm} @$ $\mathrm{NaYF}_{4}: \mathrm{Tb}$. Error bars are for $95 \%$ confidence intervals $(2 \sigma)$.

transfer to bring as much UV excitation toward the outer layer of the core particle. This phenomenon is paramount for obtaining strong enhancement of photocatalysis. In the case of yttrium-based nanoparticles, excited $\mathrm{Tm}^{3+}$ ions can radiate in the UV, but most of the emission will lead to visible photons unusable for photocatalysis. On the contrary for $\mathrm{Gd}^{3+}$-based particles, the higher excited levels of $\mathrm{Tm}^{3+}$ are harvested by gadolinium and transported to titania at the surface. 


\section{CONCLUSIONS}

Using a Monte-Carlo-based simulation describing the energy migration through dipole-dipole transfers in core-shell nanostructures, we were able to reproduce the tendency of the observed data in the literature. It highlights that the already published nanostructures are not yet optimized to reach the best efficacy. In the case of photocatalysis where the photoexcitation has to migrate toward the surface, our study shows that nanolayers of two to three atomic layers of the antiback-transfer intermediate shell would be more efficient by $\sim 45 \%$ compared with the one already published. This simulation model can be extended to a wide variety of complex nanosystems where energy transfer is a crucial parameter for the targeted application.

\section{ASSOCIATED CONTENT}

\section{S Supporting Information}

The Supporting Information is available free of charge on the ACS Publications website at DOI: 10.1021/acs.jpcc.7b10113.

Energy levels diagrams of the ions studied, track examples, typical calculation times, additional calculation results, and details of the calculation procedure. (PDF)

\section{AUTHOR INFORMATION}

\section{Corresponding Author}

*E-mail: gilles.ledoux@univ-lyon1.fr. Tel: +33 (0)4 724483 38.

\section{ORCID $\odot$}

G. Ledoux: 0000-0002-0867-1285

S. Mishra: 0000-0003-2846-4221

\section{Notes}

The authors declare no competing financial interest.

The software described in this article is available on request to the first author.

\section{ACKNOWLEDGMENTS}

We acknowledge the funding from Agence Nationale de la Recherche through the grant number ANR-17-CE09-0002.

\section{REFERENCES}

(1) Bloembergen, N. Solid State Infrared Quantum Counters. Phvs. Rev. Lett. 1959, 2, 84-85.

(2) Auzel, F. Compteur Quantique par Transfert d'Energie de $\mathrm{Yb}^{3+}$ $\mathrm{Tm}^{3+}$ dans un Tungstate Mixte et dans un Verre Germanate. C. $\underline{R}$. Acad. Sci. 1966, 263, 819-821.

(3) Auzel, F. Compteur Quantique par Transfert d'Energie Entre Deux Ions de Terres Rares dans un Tungstate Mixte et dans un Verre. C. R. Acad. Sci. 1966, 262, 1016-1019.

(4) Wang, F.; Banerjee, D.; Liu, Y.; Chen, X.; Liu, X. Upconversion Nanoparticles in Biological Labeling, Imaging, and Therapy. Analyst 2010, 135, 1839-1854.

(5) van Sark, W. G.; de Wild, J.; Rath, J. K.; Meijerink, A.; Schropp, R. E. Upconversion in Solar Cells. Nanoscale Res. Lett. 2013, 8, 81.

(6) Wang, F.; Deng, R.; Wang, J.; Wang, Q.; Han, Y.; Zhu, H.; Chen, $\mathrm{X}$.; Liu, X. Tuning Upconversion Through Energy Migration in Coreshell Nanoparticles. Nat. Mater. 2011, 10, 968-973.

(7) Zhong, Y.; Rostami, I.; Wang, Z.; Dai, H.; Hu, Z. Energy Migration Engineering of Bright Rare-Earth Upconversion Nanoparticles for Excitation by Light-Emitting Diodes. Adv. Mater. 2015, $27,6418-6422$.

(8) Li, X.; Liu, X.; Chevrier, D. M.; Qin, X.; Xie, X.; Song, S.; Zhang, H.; Zhang, P.; Liu, X. Energy Migration Upconversion in Manganese-
(II)-Doped Nanoparticles. Angew. Chem., Int. Ed. 2015, 54, 1331213317.

(9) Shen, J.; Chen, G.; Vu, A.-M.; Fan, W.; Bilsel, O. S.; Chang, C.C.; Han, G. Engineering the Upconversion Nanoparticle Excitation Wavelength: Cascade Sensitization of Tri-doped Upconversion Colloidal Nanoparticles at $800 \mathrm{~nm}$. Adv. Opt. Mater. 2013, 1, 644650.

(10) Tu, L.; Liu, X.; Wu, F.; Zhang, H. Excitation Energy Migration Dynamics in Upconversion Nanomaterials. Chem. Soc. Rev. 2015, 44, 1331-1345.

(11) Wang, X.; Xu, T.; Bu, Y.; Yan, X. Giant Enhancement of Upconversion Emission in $\mathrm{NaYF}_{4}: \mathrm{Er}^{3+} @ \mathrm{NaYF}_{4}: \mathrm{Yb}^{3+}$ Active-core/ Active-shell Nanoparticles. RSC Adv. 2016, 6, 22845-22851.

(12) Quintanilla, M.; Ren, F.; Ma, D.; Vetrone, F. Light Management in Upconverting Nanoparticles: Ultrasmall Core/Shell Architectures to Tune the Emission Color. ACS Photonics 2014, 1, 662-669.

(13) Xie, X.; Gao, N.; Deng, R.; Sun, Q.; Xu, Q.-H.; Liu, X. Mechanistic Investigation of Photon Upconversion in $\mathrm{Nd}^{3+}$ -Sensitized Core-Shell Nanoparticles. I. Am. Chem. Soc. 2013, 135, 12608-12611.

(14) Zhou, B.; Yang, W.; Han, S.; Sun, Q.; Liu, X. Photon Upconversion Through $\mathrm{Tb}^{3+}$-Mediated Interfacial Energy Transfer. Adv. Mater. 2015, 27, 6208-6212.

(15) Chan, E. M.; Levy, E. S.; Cohen, B. E. Rationally Designed Energy Transfer in Upconverting Nanoparticles. Adv. Mater. 2015, 27, 5753-5761.

(16) Su, Q.; Han, S.; Xie, X.; Zhu, H.; Chen, H.; Chen, C.-K.; Liu, R.-S.; Chen, X.; Wang, F.; Liu, X. The Effect of Surface Coating on Energy Migration-Mediated Upconversion. I. Am. Chem. Soc. 2012, 134, 20849-20857.

(17) Huang, Q.; Yu, H.; Zhang, X.; Cao, W.; Yu, J. Upconversion Performance Enhancement of $\mathrm{NaYF}_{4}: \mathrm{Yb} / \mathrm{Tm}$ by Codoping $\mathrm{Hf}^{4+}$ as Energy Migrator. Huaxue Xuebao 2016, 74, 191-198.

(18) Wen, H.; Zhu, H.; Chen, X.; Hung, T. F.; Wang, B.; Zhu, G.; Yu, S. F.; Wang, F. Upconverting Near-Infrared Light through Energy Management in Core-Shell-Shell Nanoparticles. Anoew. Chem. Int. Ed. 2013, 52, 13419-13423.

(19) Villanueva-Delgado, P.; Krämer, K. W.; Valiente, R. Simulating Energy Transfer and Upconversion in $\beta-\mathrm{NaYF}_{4}: \mathrm{Yb}^{3+}, \mathrm{Tm}^{3+}$. $\underline{\text { L Phys. }}$. Chem. C 2015, 119, 23648-23657.

(20) Chen, X. Y.; Zhuang, H. Z.; Liu, G. K.; Li, S.; Niedbala, R. S. Confinement on Energy Transfer Between Luminescent Centers in Nanocrystals. I. Appl. Phys. 2003, 94, 5559-5565.

(21) Pawlik, G.; Niczyj, J.; Noculak, A.; Radosz, W.; Podhorodecki, A. Multiband Monte Carlo Modeling of Upconversion Emission in Sub $10 \mathrm{~nm} \beta$ - $\mathrm{NaGdF}_{4}: \mathrm{Yb}^{3+} / \mathrm{Er}^{3+}$ Nanocrystals - Effect of $\mathrm{Yb}^{3+}$ Content. I. Chem. Phys. 2017, 146, 244111.

(22) Wang, J.; Deng, R.; MacDonald, M. A.; Chen, B.; Yuan, J.; Wang, F.; Chi, D.; Hor, T. S. A.; Zhang, P.; Liu, G.; et al. Enhancing Multiphoton Upconversion Through Energy Clustering at Sublattice Level. Nat. Mater. 2013, 13, 157-162.

(23) Liu, Y.; Lu, Y.; Yang, X.; Zheng, X.; Wen, S.; Wang, F.; Vidal, X.; Zhao, J.; Liu, D.; Zhou, Z.; et al. Amplified Stimulated Emission in Upconversion Nanoparticles for Super-Resolution Nanoscopy. Nature 2017, 543, 229-233.

(24) Forster, T. Zwischenmolekulare Energiewanderung und Fluoreszenz. Ann. Phvs. (Berlin, Ger.) 1948, 437, 55-75.

(25) Kiliaan, H. S.; Kotte, J. F. A. K.; Blasse, G. Energy Transfer in the Luminescent System $\mathrm{Na}(\mathrm{Y}, \mathrm{Gd}) \mathrm{F}_{4}: \mathrm{Ce}, \mathrm{Tb}$. I. Electrochem. Soc. 1987, 134, 2359-2364.

(26) Grzechnik, A.; Friese, K. Crystal Structures and Stability of NaLnF4 (Ln = La, Ce, Pr, Nd, Sm and Gd) Studied with Synchrotron Single-crystal and Powder Diffraction. Dalton Trans. 2012, 41, $10258-10266$.

(27) Zhang, X.; Wang, M.; Ding, J.; Gao, D.; Shi, Y.; Song, X. The Novel Upconversion Properties of $\mathrm{LiYbF}_{4}$ :Er Microcrystals Compared to the Na Counterpart. CrustEngComm 2012, 14, 8357-8360. 
(28) Fournier, M. T.; Zakaria, D.; Arbus, A.; Cousseins, J. C. Fluorescence Dynamics of the $\mathrm{Tb}^{3+}$ Ion in Hexagonal $\mathrm{NaYF}_{4}$. I. LessCommon Met. 1989, 153, 79-87.

(29) Blasse, G.; Grabmaier, B. C. Luminescent Materials; Springer: Berlin, 1994.

(30) Wang, W.; Li, Y.; Kang, Z.; Wang, F.; Yu, J. C. A NIR-driven Photocatalyst Based on $\alpha-\mathrm{NaYF}_{4}: \mathrm{Yb}, \mathrm{Tm} @ \mathrm{TiO}_{2}$ Core-shell Structure Supported on Reduced Graphene Oxide. Appl. Catal. B 2016, 182, 184-192.

(31) Tang, Y.; Di, W.; Zhai, X.; Yang, R.; Qin, W. NIR-Responsive Photocatalytic Activity and Mechanism of $\mathrm{NaYF}_{4}: \mathrm{Yb}, \mathrm{Tm} @ \mathrm{TiO}_{2}$ Core-Shell Nanoparticles. ACS Catal. 2013, 3, 405-412.

(32) Wang, W.; Ding, M.; Lu, C.; Ni, Y.; Xu, Z. A Study on Upconversion UV-vis-NIR Responsive Photocatalytic Activity and Mechanisms of Hexagonal Phase $\mathrm{NaYF}_{4}: \mathrm{Yb}^{3+}, \mathrm{Tm}^{3+} @ \mathrm{TiO}_{2}$ Core-shell Structured Photocatalyst. Appl. Catal. B 2014, 144, 379-385.

(33) Zhang, Y.; Hong, Z. Synthesis of Lanthanide-doped NaYF $@$ $\mathrm{TiO}_{2}$ Core-shell Composites with Highly Crystalline and Tunable $\mathrm{TiO}_{2}$ Shells Under Mild Conditions and their Upconversion-based Photocatalysis. Nanoscale 2013, 5, 8930-8933.

(34) Ullah, S.; Hazra, C.; Ferreira-Neto, E. P.; Silva, T. C.; Rodrigues-Filho, U. P.; Ribeiro, S. J. L. Microwave-assisted Synthesis of $\mathrm{NaYF}_{4}: \mathrm{Yb}^{3+} / \mathrm{Tm}^{3+}$ Upconversion Particles with Tailored Morphology and Phase for the Design of UV/NIR-active $\mathrm{NaYF}_{4}: \mathrm{Yb}^{3+} / \mathrm{Tm}^{3+} @$ $\mathrm{TiO}_{2}$ Core@shell Photocatalysts. CrvstEngComm 2017, 19, 34653475.

(35) Chen, Y.; Mishra, S.; Ledoux, G.; Jeanneau, E.; Daniel, M.; Zhang, J.; Daniele, S. Direct Synthesis of Hexagonal $\mathrm{NaGdF}_{4}$ Nanocrystals from a Single-Source Precursor: Upconverting NaGd$\mathrm{F}_{4}: \mathrm{Yb}^{3+}, \mathrm{Tm}^{3+}$ and Its Composites with $\mathrm{TiO}_{2}$ for Near-IR-Driven Photocatalysis. Chem. - Asian J. 2014, 9, 2415-2421. 